\title{
Association between interleukin 4 (IL-4) VNTR, gene polymorphism, and breast cancer susceptibility in Iranian population: experimental and web base analysis
}

\author{
Ibrahimi $\mathrm{M}^{1,2^{*}}$, Jamalzei $\mathrm{B}^{2 *}$, Akbari $\mathrm{ME}^{1}$, Ibrahimi R, Alaei M, MoossaviM ${ }^{4,5}$, \\ Mohammadoo-Khorasani $\mathrm{M}^{2}$ \\ Cancer Research Center, Shahid Beheshti University of Medical Sciences, Tehran, IR Iran. \\ miladkh24@yahoo.com
}

\begin{abstract}
BACKGROUND: Breast cancer (BC) is one of the most common types of cancer and the second leading cause of cancer death among women. Epidemiological studies showed that BC is linked to genetic and environmental factors, and inheritance plays a key role in the pathobiology of this disease. Interleukin 4 (IL-4) is a key differentiation cytokine and is produced by Th2 and activates Th2 development. Hence the current study aimed to assess the possible association between interleukin 4 (IL-4) VNTR polymorphism, and BC susceptibility in a sample of Iranian population.

MATERIAL AND METHODS: IL-4 VNTR polymorphism was evaluated in 150 women with BC and 150 agematched healthy women by polymerase chain reaction method.

RESULT: Among 3 possible alleles for IL-4 gene, we only observed 2 alleles. Current findings indicate that $\mathrm{RP} 2 / \mathrm{RP} 2$ genotypes can be regarded as potent protective factors against breast cancer $(\mathrm{OR}=0.929[95 \% \mathrm{Cl}$, 0.929-0.995]).

CONCLUSION: Our result showed that the RP2/RP2 genotype of the IL-4 VNTR polymorphism could be a protective factor for BC susceptibility (Tab. 2, Fig. 1, Ref. 46).

KEY WORDS: IL-4, breast cancer, VNTR polymorphism.
\end{abstract}

\section{Introduction}

Breast cancer with 252710 estimated new cases in 2017 in United States is the most common type of cancer worldwide (1, 2). Although the incidence rate is decreasing, in developed countries it is still the leading cause of cancer mortality. There are legion risk factors related to breast cancer such as: age, genetic background, hormonal condition, obesity, exposure to radiation and chemical carcinogens. Histopathological markers, including the expression of sex hormone receptors and human epidermal growth factor receptor (HER2) are commonly used as diagnostic means to contribute to choosing an effective approach in clinical treatment (3-6). Almost 60 to $70 \%$ of breast cancer cases are ER/PR positive and so tumor growth is dependent on estro-

${ }^{1}$ Cancer Research Center, Shahid Beheshti University of Medical Sciences, Tehran, IR Iran, ${ }^{2}$ Department of Clinical Biochemistry, Faculty of Medical Sciences, Tarbiat Modares University, Tehran, Iran, ${ }^{3}$ Research Committee, Faculty of Medicine, Mashhad University of Medical Sciences Mashhad, Iran, ${ }^{4}$ Research Committee, Birjand University of Medical Sciences, Birjand, Iran, and ${ }^{5}$ Department of Molecular Medicine, Birjand University of Medical Sciences, Birjand, Iran

Address for correspondence: M. Mohammadoo-Khorasani, Department of Clinical Biochemistry, Faculty of Medical Sciences, Tarbiat Modares University, Tehran, Iran.

${ }^{*}$ M. Ibrahimi and B. Jamalzei have equally contributed as first author. gen. And also, 20 to $25 \%$ over-express Her2, which are more aggressive $(7,8)$. About $30 \%$ of ER positive tumor and more than $70 \%$ of tumors, which overexpress Her2, respond poorly to specific therapies related to these biomarkers. Moreover, 10 to $20 \%$ of breast cancer patients are classified as triple negative, which are more aggressive and lack target for specific treatment (9). Consequently, these markers are not sufficient to cover the heterogeneity of breast cancer and in turn resort to accurate prediction of treatment outcome (10). In order to dwindle any over or under treatment and ultimately determine an optimal therapy, introducing new biomarkers is considered to be of paramount importance. Numerous studies are claiming to identify factors or profiles that predict response to treatment or influence patient survival whereas, only a small portion, of which has been reported, are validated by organizations in authority such as American society of clinical oncology. However, a substantial set of newly introduced markers are shown to have a promising potential to be used in future (11). Information provided from molecular studies have also brought novel and deeper view of breast cancer complexity and lead to improvement of breast cancer molecular classification and more comprehensive understanding of the clinical respect of the disease (12).

Therefore, genetic variation associated with risk of breast cancer has been studied widely, hoping that polymorphism genotyping will stratify breast cancer risk more accurately (13-15). 
$651-654$

Interleukin 4 (IL-4) is an important differentiation cytokine produced by Th2 and activates Th2 development. Th2 subset of lymphocytes have the responsibility of tumor cell clearance by the means of granulocytes and Eosinophils activation and also inhibition of angiogenesis (16-18). As a further matter, Th2 subset antagonize IFN- $\gamma$, inhibit macrophage activation and its anti-tumor function on variety of cancers such as: colon, breast cancer and renal cancer were reported by some studies $(19,20)$. However, it has been reported that IL-4 can act as a double edge sword in controlling tumor growth. It has been reported that IL- 4 contribute to initiation, progression and metastasis of head and neck carcinoma (20) and higher levels of IL-4 mRNA were found in more advanced stages of gastric cancer (20). Besides, IL-4 interfere with anti-tumor immunity by down-regulating of TH1 cytokines (19, 21). Legion of surveys were conducted on several IL-4 polymorphism in order to determine its contribution on human cancer risk. Among which, one paramount polymorphism is a variable number of tandem repeats (VNTR) of a 70-bp sequence located in intron $3(22,23)$. In the present study, we aimed to assess the probable association between 70-bp VNTR polymorphism of the IL4 gene and the risk of breast cancer in Iranian population.

\section{Material and methods}

\section{Study population}

In this study a total number of 300 subjects were recruited, 150 cases with breast cancer and 150 healthy control samples. Breast cancer patient's sample was provided by cancer research center of Shahid Beheshti University of Medical science. This study was approved by ethical committee of Shahid Beheshti University of Tehran, Iran (Ethical code: IR.SBMU.REC.1396.133). Control women were assessed and confirmed of having no detectable breast cancer at the time of sampling and had no personal or family history of cancer.

\section{IL-4 Genotyping}

Genomic DNA was extracted from peripheral blood mononuclear cells using salting-out method. Polymerase chain reaction (PCR) was conducted to analyze the 70 bp VNTR of IL-4 gene intron 3. Oligonucleotide primers were as followed: forward: 5 'AGGCTGAAAGGGGGAAAGC-3', reverse: 5'CTGTTCACCTCAACTGCTCC-3'(24). PCR reactions were performed in $25 \mu \mathrm{L}$ final volume containing $25 \mathrm{pmol}$ of each primer, $0.1 \mathrm{mmol} \mathrm{dNTP}$, (Fermentas, Lithuania), $1 \mu$ g genomic DNA, $1.5 \mathrm{mM} \mathrm{MgCl}_{2}, 1.5$ unit of taq DNA polymerase and $2.5 \mu \mathrm{L}$ of PCR buffer according the protocol following: $94^{\circ} \mathrm{C}$ for 5 minute for initial denaturation, following denaturation at $94{ }^{\circ} \mathrm{C}$ for 50 seconds, 30 seconds at 62 ${ }^{\circ} \mathrm{C}$ for annealing, 30 second at $72{ }^{\circ} \mathrm{C}$ for extension and 5 minute at $72{ }^{\circ} \mathrm{C}$ for final extension. Stage 2 to 4 was repeated for 30 cycles. $2 \%$ agarose gel was used to electrophorese PCR product and visualization has been done using safe stain.

\section{Web base analysis}

A meta-analysis of gene markers obtained from breast cancer cell microarray database and disease-free survival data collected by the Gene Expression Omnibus (NCBI, Bethesda, MD, USA; http://www.ncbi.nlm. nih.gov/geo) was conducted by the use of analytic tools generated by Gyorffy et al (25) and facilitated by the Kaplan-Meier Plotter (http://www. kmplot.com), a web-based analysis tool.

\section{Statistical analysis}

Data analysis was performed using SPSS V.22 software. Independent sample $t$-test $\chi^{2}$ test or Fisher's exact test was used to evaluate the differences. Allele frequency was determined by using a direct gen counting method. Allele frequency between breast cancer patients and the control group was compared by $\chi^{2}$ test and Fisher's exact test. The odd ratio (OR) and $95 \%$ confidence intervals $(95 \% \mathrm{CI})$ had also been calculated. $\mathrm{p}<0.05$ was considered statistically significant.

\section{Results}

Demographic data of the breast cancer patients and the control group is shown in the Table 1.

Tab. 1. Demographic and clinical characteristics of the study population.

\begin{tabular}{lcc}
\hline & Normal $(\mathrm{n}=150)$ & Malignant $(\mathrm{n}=150)$ \\
\hline Age (year) & & \\
$<40$ & $30(20 \%)$ & $26(17 \%)$ \\
$40-60$ & $90(60 \%)$ & $84(56 \%)$ \\
$>60$ & $30(20 \%)$ & $40(27 \%)$ \\
\hline Grade & & \\
1 & $18(12 \%)$ \\
2 & & $101(67 \%)$ \\
3 & & $31(21 \%)$ \\
\hline Stage & \\
I & $31(21 \%)$ \\
II & $66(44 \%)$ \\
III & $63(35 \%)$ \\
\hline ER/PR & \\
Positive & $104(69 \%)$ \\
Negative & $46(29 \%)$ \\
\hline c-erbB2 & \\
Positive & $46(29 \%)$ \\
Negative & $104(69 \%)$ \\
\hline
\end{tabular}

Tab. 2. Genotypes and Alleles Frequency of IL4 VNTR Polymorphism.

\begin{tabular}{|c|c|c|c|c|}
\hline Genotype & $\begin{array}{l}\text { Control } \\
(\mathrm{n}=150)\end{array}$ & $\begin{array}{c}\text { Case } \\
(\mathrm{n}=150)\end{array}$ & $\mathrm{p}$ & $\begin{array}{c}\text { OR } \\
(95 \% \mathrm{CI})\end{array}$ \\
\hline $\mathrm{RP} 1 / \mathrm{RP} 1$ & 124 & 119 & Ref $=1$ & \\
\hline $\mathrm{RP} 1 / \mathrm{RP} 2$ & 21 & 31 & 0.107 & $1.53(0.837-2.826)$ \\
\hline $\mathrm{RP} 2 / \mathrm{RP} 2$ & 5 & 0 & 0.037 & \\
\hline \multicolumn{5}{|l|}{ Dominant } \\
\hline RP1/RP1 & 124 & 119 & & \\
\hline $\mathrm{RP} 1 / \mathrm{RP} 2+\mathrm{RP} 2 / \mathrm{RP} 2$ & 26 & 31 & 0.27 & $1.242(0.697-2.26)$ \\
\hline \multicolumn{5}{|l|}{ Recessive } \\
\hline $\mathrm{RP} 2 / \mathrm{RP} 2$ & 5 & 0 & & \\
\hline $\mathrm{RP} 1 / \mathrm{RP} 1+\mathrm{RP} 1 / \mathrm{RP} 1$ & 145 & 150 & 0.03 & - \\
\hline \multicolumn{5}{|l|}{ Allele } \\
\hline RP1 & 269 & 269 & $\operatorname{Ref}=1$ & \\
\hline $\mathrm{RP} 2$ & 31 & 31 & 0.553 & $1(0.59-1.69)$ \\
\hline
\end{tabular}




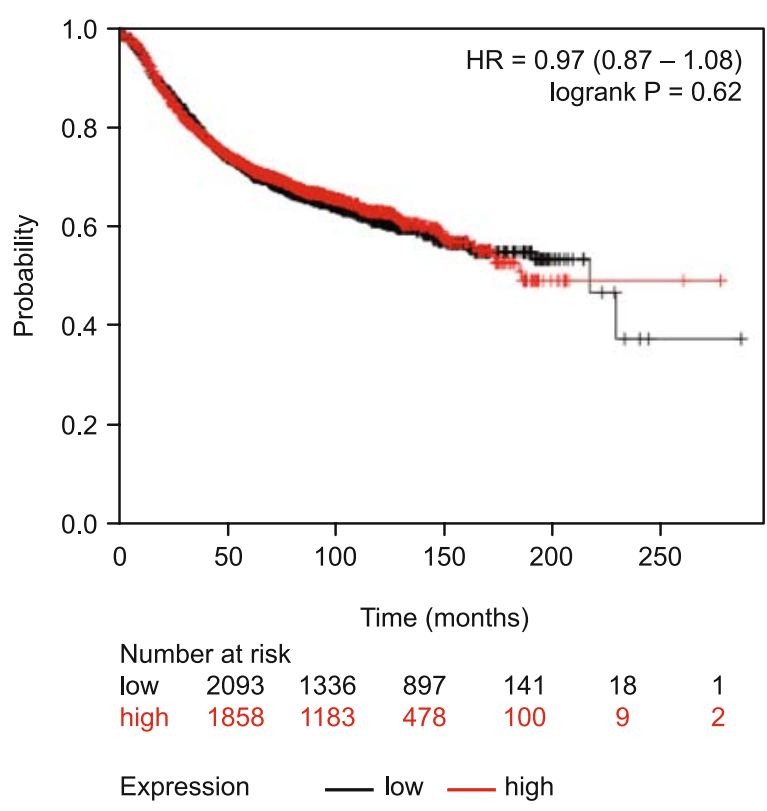

Fig. 1. Kaplan Meier plot for il-4 expression in breast cancer.

Using web analysis, no significant difference in survival was found between low expression of IL-4 and high expression of IL-4 $(p=0.615)$. However, data collected from this study indicates that low expression of IL-4 is associated with better survival in breast cancer patients (Fig. 1).

Among 3 possible alleles for IL-4 gene, we only observed 2 alleles. Allelic and genotypic frequency distributions of the IL-4 VNTR are shown in the Table 2. Current findings indicate that $\mathrm{RP} 2 / \mathrm{RP} 2$ genotypes can be regarded as potent protective factors against breast cancer $(\mathrm{OR}=0.929$ [95\%CI, 0.929-0.995]).

\section{Discussion}

Cancer, as a heterogeneous disease, is caused by complex interaction of environment and genetic influence, which results in a poor clinical outcome predictability (26-28). Inflammation as an inherent characteristic of cancer is associated with development, invasion, and metastasis, however, many types of cancer cells evade immune system. Cancer inflammation is exerted and controlled by chemokines, prostaglandins, and cytokines (29). Among which, as the key inflammatory cytokine, IL-4 has been linked with various types of cancer. It is shown that elevated plasma levels of IL-4 were linked with the risk of melanoma, head and neck squamous carcinoma, prostate, colon, renal cell, small cell lung cancer, acute myeloid leukemia and breast cancer (30-33). Moreover, several polymorphism related to IL-4 encoding gene were shown to be a cancer risk factor (34-38). Among which, intron 3 VNTR polymorphism has a paramount role in controlling IL-4 production. Our results indicated that frequency of RP2/ RP2 genotype was significantly higher in healthy, control group. Furthermore, Several studies indicated that Th1/Th2 balance was altered in cancer $(39,40)$. IL-4 VNTR polymorphism is located in intron 3 of IL-4 gene and could change messenger ribonucleic acid splicing, which subsequently leads to different splice variants, which can effect gene expression (18). It is also reported that RP2/ RP2 genotype is associated with a low expression of this cytokine (41). We have also found a higher frequency of RP2/RP2 in the control group. This finding supports the fact that serum levels of interlukine 4 in breast cancer are decreased (42). Contradictory, in a meta-analysis study performed by Li et al, no association was found between IL-4 polymorphism and cancer risk (43). In another meta-analysis, Duan et al. reported that RP2 allele was associated with a decreased cancer risk (44). On the other hand, Konwar et al. indicated a lack of association between VNTR polymorphism of IL-4 and breast cancer. However, RP2/RP2 genotype in patients affected with breast cancer was significantly less frequent than in normal individuals (45). Besides, according to Shekari et al findings, RP1/RP2 genotype frequencies in cervical cancer patient were significantly higher than in healthy women (46). These observations supported the theory that immunological, inflammatory, and anti-inflammatory processes could play key roles in breast cancer development. At the end it is worth mentioning that this study faced some difficulties such as: low sample size, different ethnic groups and environmental conditions. Ergo, in order to minimize the confounding variables, more extensive studies in sample size are recommended for a better understanding of the pathogenetic role of IL-4VNTR polymorphism in breast cancer.

\section{References}

1. Crew KD, Albain KS, Hershman DL, Unger JM, Lo SS. How do we increase uptake of tamoxifen and other anti-estrogens for breast cancer prevention? Breast Cancer 2017; 3 (1): 20.

\section{2. https: //seer.cancer.gov/statfacts/html/breast.html.}

3. Hamam R, Hamam D, Alsaleh KA, Kassem M, Zaher W, Alfayez M et al. Circulating microRNAs in breast cancer: novel diagnostic and prognostic biomarkers. Cell Death Disease 2017; 8 (9): e3045.

4. Hashemi S, Sadeghi M, Vahedi Tabas A, Bouya S, Danesh HA, Khazaei A et al. Serum Levels of Selenium and Zinc in Patients with Breast Cancer: A Case-Control Study. Int J Cancer Manag 2017; 10 (12): e11463.

5. Tabarestani S, Motallebi M, Akbari ME, Malekzadeh Moghani M, Shojaee L. Analysis of BRCA1/2 Mutations and Performance of Manchester Scoring System in High Risk Iranian Breast Cancer Patients: A Pilot Study. Int J Cancer Manag 2017; 10 (12): e60392.

6. Zahmatkesh BH, Alavi N, Keramat A, Khosravi A, Chaman R. Body Mass Index and Risk of Breast Cancer: A Systematic Review and MetaAnalysis in Iran. Int J Cancer Manag 2017; 10 (4): e5921.

7. Wu Y, Khan H, Chillar R, Vadgama JV. Prognostic value of plasma HER-2/neu in African American and Hispanic women with breast cancer. Internat J Oncol 1999; 14 (6): 1021-1058.

8. Hynes NE, Stern DF. The biology of erbB-2/nue/HER-2 and its role in cancer. Biochim Biophys Acta 1994; 1198 (2-3): 165-184.

9. Carey LA, Perou CM, Livasy CA, Dressler LG, Cowan D, Conway K et al. Race, breast cancer subtypes, and survival in the Carolina Breast Cancer Study. JAMA 2006; 295 (21): 2492-502.

10. Dowsett M, Dunbier AK. Emerging biomarkers and new understanding of traditional markers in personalized therapy for breast cancer. Clin Cancer Res 2008; 14 (24): 8019-8026. 
11. Copur MS, Ramaekers R, Gauchan D, Norvell M, Clark D. Recent ASCO guideline on the use of biomarkers for adjuvant systemic therapy in early-stage invasive breast cancer. J Clin Oncol 2016; 34 (32): 3943-3944.

12. Lánczky A, Nagy Á, Bottai G, Munkácsy G, Szabó A, Santarpia L et al. miRpower: a web-tool to validate survival-associated miRNAs utilizing expression data from 2178 breast cancer patients. Breast Cancer Res Treatm 2016; 160 (3): 439-446.

13. Wang C-Q, Tang C-H, Wang Y, Jin L, Wang Q, Li X et al. FSCN1 gene polymorphisms: biomarkers for the development and progression of breast cancer. Sci Report 2017; 7 (1): 15887.

14. Sanjari Moghaddam A, Nazarzadeh M, Noroozi R, Darvish H, Mosavi Jarrahi A. XRCC1 and OGG1 Gene Polymorphisms and Breast Cancer: A Systematic Review of Literature. Int J Cancer Manag 2016; 9 (1): e3467.

15. Kholousi Adab F, Tahmasebi Fard Z, Esmaeil Akbari M. Association Between Cytochrome 1B1*3 Polymorphism and the Breast Cancer in a Group of Iranian Women. Int J Cancer Manag 2017; 10 (1): e6428.

16. Olver S, Apte S, Baz A, Kienzle N. The duplicitous effects of interleukin 4 on tumour immunity: how can the same cytokine improve or impair control of tumour growth? HLA 2007; 69 (4): 293-298.

17. Swain S, Weinberg A, English M, Huston G. IL-4 directs the development of Th2-like helper effectors. J Immunol 1990; 145 (11): 3796-3806.

18. Salimi S, Mohammadoo-Khorasani M, Yaghmaei M, Mokhtari M, Moossavi M. Possible association of IL-4 VNTR polymorphism with susceptibility to preeclampsia. BioMed Res Internat 2014; 2014.

19. Myers JN, Yasumura S, Suminami Y, Hirabayashi H, c Lin W, Johnson JT et al. Growth stimulation of human head and neck squamous cell carcinoma cell lines by interleukin 4. Clin Cancer Res 1996; 2 (1): 127-135.

20. Yamamoto T, Yoneda K, Ueta E, Hirota J, Osaki T. Serum cytokine levels in patients with oral mucous membrane disorders. J Oral Pathol Med 1991; 20 (6): 275-279.

21. Goto T, Nishizono A, Fujioka T, Ikewaki J, Mifune K, Nasu M. Local secretory immunoglobulin A and postimmunization gastritis correlate with protection against Helicobacter pylori infection after oral vaccination of mice. Infection Immun 1999; 67 (5): 2531-2539.

22. Rosenwasser L, Klemm D, Dresback J, Inamura H, Mascali J, Klinnert $\mathrm{M}$ et al. Promoter polymorphisms in the chromosome 5 gene cluster in asthma and atopy. Clin Exp Allergy 1995; 25 (s2): 74-78.

23. Mout R, Willemze R, Landegent J. Repeat polymorphisms in the interleukin 4 gene (IL4). Nucl Acids Res 1991; 19 (13): 3763.

24. Mohammadoo-Khorasani M, Salimi S, Tabatabai E, Sandoughi M, Zakeri Z, Farajian-Mashhadi F. Interleukin-1 $\beta$ (IL-1 $\beta$ ) \& IL-4 gene polymorphisms in patients with systemic lupus erythematosus (SLE) \& their association with susceptibility to SLE. Indian J Med Res 2016; 143 (5): 591.

25. Györffy B, Lanczky A, Eklund AC, Denkert C, Budczies J, Li Q et al. An online survival analysis tool to rapidly assess the effect of 22,277 genes on breast cancer prognosis using microarray data of 1,809 patients. Breast Cancer Res Treat 2010; 123 (3): 725-731.

26. Zhang H, Xu Y, Zhang Z, Liu R, Ma B. Association between COX-2 rs2745557 polymorphism and prostate cancer risk: a systematic review and meta-analysis. BMC Immunol 2012; 13 (1): 14.

27. Zhang H, Qi C, Li L, Luo F, Xu Y. Clinical significance of NUCB2 mRNA expression in prostate cancer. J Exp Clin Cancer Res 2013; 32 (1): 56.

28. Abaza M, Bahman A, Al-Attiyah R, Kollamparambil A. Synergistic induction of apoptosis and chemosensitization of human colorectal cancer cells by histone deacetylase inhibitor, scriptaid, and proteasome inhibitors: potential mechanisms of action. Tumor Biol 2012; 33 (6): 1951-1972.
29. Harvey RD, Morgan E. Cancer, Inflammation, and Therapy: Effects on Cytochrome P450-Mediated Drug Metabolism and Implications for Novel Immunotherapeutic Agents. Clin Pharmacol Ther 2014; 96 (4): 449-457.

30. Sanchez-Correa B, Bergua JM, Campos C, Gayoso I, Arcos MJ, Bañas $\mathrm{H}$ et al. Cytokine profiles in acute myeloid leukemia patients at diagnosis: survival is inversely correlated with IL-6 and directly correlated with IL-10 levels. Cytokine 2013; 61 (3): 885-891.

31. Porter GA, Abdalla J, Lu M, Smith S, Montgomery D, Grimm E et al. Significance of plasma cytokine levels in melanoma patients with histologically negative sentinel lymph nodes. Annal Surg Oncol 2001; 8 (2): 116-122.

32. Lathers DM, Young MRI. Increased aberrance of cytokine expression in plasma of patients with more advanced squamous cell carcinoma of the head and neck. Cytokine 2004; 25 (5): 220-228.

33. Shurin MR, Lu L, Kalinski P, Stewart-Akers AM, Lotze MT, editors. Th1/Th2 balance in cancer, transplantation and pregnancy. Springer Semin Immunopathol 1999: Springer.

34. Bozdoğan S, Erol B, Dursun A, Bozdoğan G, Dönmez I, Mungan N et al. The IL-1RN and IL-4 gene polymorphisms are potential genetic markers of susceptibility to bladder cancer: a case control study. World J Urol 2015; 33 (3): 389-395.

35. Pan X-F, Wen Y, Loh M, Wen Y-Y, Yang S-J, Zhao Z-M et al. Interleukin 4 and-8 gene polymorphisms and risk of gastric cancer in a population in Southwestern China. Asian Pac J Cancer Prev 2014; 15 (7): 2951-2957.

36. Jin T, Li X, Zhang J, Wang $\mathbf{H}$, Geng $\mathbf{T}$, Li $\mathbf{G}$ et al. Genetic association between selected cytokine genes and glioblastoma in the Han Chinese population. BMC Cancer 2013; 13 (1): 236.

37. Monroy CM, Cortes AC, Lopez MS, D'amelio AM, Etzel CJ, Younes A et al. Hodgkin disease risk: role of genetic polymorphisms and gene-gene interactions in inflammation pathway genes. Mol Carcinogen 2011; 50 (1): 36-46.

38. Olson SH, Orlow I, Simon J, Tommasi D, Roy P, Bayuga S et al. Allergies, variants in IL-4 and IL-4R $\alpha$ genes, and risk of pancreatic cancer. Cancer Detection Prevent 2007; 31 (5): 345-351.

39. Green VL, Alexandropoulou A, Walker MB, Walker AA, Sharp DM, Walker LG et al. Alterations in the Th1/Th2 balance in breast cancer patients using reflexology and scalp massage. Exp Ther Med 2010; 1 (1): 97-108.

40. Li J, Wang Z, Mao K, Guo X. Clinical significance of serum T helper $1 /$ T helper 2 cytokine shift in patients with non-small cell lung cancer. Oncol Lett 2014; 8 (4): 1682-1686.

41. Cabantous S, Poudiougou B, Oumar AA, Traore A, Barry A, Vitte J et al. Genetic evidence for the aggravation of Plasmodium falciparum malaria by interleukin 4. J Infect Dis 2009; 200 (10): 1530-1539.

42. Al-Ghurabi BH. IL-2 and IL-4 serum levels in breast cancer. J Fac Med Baghdad 2009; 51 (3): 300-303.

43. Zhenzhen L, Xianghua L, Qingwei W, Zhan G, Ning S. Three common polymorphisms in the IL-4 gene and cancer risk: a meta-analysis involving 5,392 cases and 6,930 controls. Tumor Biol 2013; 34 (4): 2215-2224.

44. Duan Y, Pan C, Shi J, Chen H, Zhang S. Association between interleukin 4 gene intron 3 VNTR polymorphism and cancer risk. Cancer Cell Int 2014; 14 (1): 131.

45. Konwar R, Chaudhary P, Kumar S, Mishra D, Chattopadhyay N, Bid HK. Breast cancer risk associated with polymorphisms of IL-1RN and IL-4 gene in Indian women. Oncol Res Featuring Preclin Clin Cancer Ther 2009; 17 (8): 367-372.

46. Shekari M, Kordi-Tamandani DM, MalekZadeh K, Sobti RC, Karimi S, Suri V. Effect of anti-inflammatory (IL-4, IL-10) cytokine genes in relation to risk of cervical carcinoma. Am J Clin Oncol 2012; 35 (6): 514-519.

Received May 26, 2018. Accepted June 4, 2018. 